\title{
Gambaran Kejadian Postoperative Nausea and Vomiting (PONV) pada Pasien Pasca Tindakan Dilatasi Kuretase dengan Anestesi Umum di RSIA B pada Tahun 2019
}

\author{
Resiana Karnina ${ }^{1}$, Mayinda Nabilla Ismah ${ }^{2}$ \\ 1) Departemen Anastesi, Fakultas Kedokteran dan Kesehatan, Universitas Muhammadiyah Jakarta, Indonesia \\ 2) Program Studi Kedokteran, Fakultas Kedokteran dan Kesehatan, Universitas Muhammadiyah Jakarta, Indonesia \\ *Corresponding author: sublime_dr@yahoo.com
}

\begin{abstract}
Background: General anesthesia is one type of anesthesia that is widely used for dilation and curettage surgery. However, general anesthesia has complications, one of which is the incidence of Postoperative Nausea and Vomiting (PONV). Purpose: Knowing the description of the incidence of Postoperative Nausea and Vomiting (PONV) in postoperative dilatation and curettage patients using general anesthesia at RSIA B in 2019. Method: The design of this research is descriptive, the data were taken from the medical records of patients after dilatation and curettage with general anesthesia at RSIA B. The sample was taken using a total sampling method of 139 samples. Data analysis using SPSS 26.0 for Windows. Results: Among 139 patients, the incidence of Postoperative Nausea and Vomiting (PONV) was 16 cases (11.5\%). PONV under general anesthesia was most prevalent in the age range 29 - 34 years (14\%) and patients with American Society of Anesthesiologists (ASA) I status (13\%). The proportion of $P O N V$ in patients based on the type of anesthetic drug, namely the type of intravenous anesthetic drug was 16 cases (11.5\%). Conclusion: The incidence of Postoperative Nausea and Vomiting (PONV) is quite high, especially in the age range $29-34$, ASA I status and intravenous anesthetic drugs.
\end{abstract}

Keywords: general anesthesia, dilatation and curettage, postoperative nausea and vomiting (PONV)

\section{ABSTRAK}

Latar Belakang: Anestesi umum merupakan salah satu jenis anestesi yang banyak digunakan untuk tindakan dilatasi dan kuretase. Meskipun demikian, anestesi umum memiliki komplikasi salah satunya yaitu kejadian Postoperative Nausea and Vomiting (PONV). Tujuan: Mengetahui gambaran kejadian Postoperative Nausea and Vomiting (PONV) pada pasien pasca tindakan dilatasi dan kuretase menggunakan anestesi umum di RSIA B pada tahun 2019. Metode: Desain penelitian ini adalah penelitian deskriptif observasional, data diambil dari catatan rekam medis pasien pasca tindakan dilatasi dan kuretase dengan anestesi umum di RSIA B. Sampel diambil dengan metode total sampling sebanyak 139 sampel. Analisa data menggunakan SPSS 26.0 for Windows. Hasil: Dari 139 pasien, angka kejadian Postoperative Nausea and Vomiting (PONV) adalah 16 kasus (11.5\%). PONV dengan anestesi umum paling banyak terjadi pada rentang usia 29 - 34 tahun (14\%) dan pasien dengan status American Society of Anesthesiologists (ASA) I (13\%). Proporsi pasien PONV berdasarkan jenis obat anestesi yaitu pada jenis obat anestesi intravena sebanyak 16 kasus (11.5\%). Simpulan: Kejadian Postoperative Nausea and Vomiting (PONV) cukup tinggi, terutama pada rentang usia 29 - 34, status ASA I dan jenis obat anestesi intravena. 
Kata kunci: anestesi umum, dilatasi dan kuretase, postoperative nausea and vomiting (PONV)

\section{PENDAHULUAN}

Tindakan dilatasi dan kuretase merupakan sebuah tindakan pembedahan untuk melebarkan leher rahim (cervix) sehingga lapisan rahim (endometrium) dapat dikikis untuk mengangkat jaringan yang abnormal. Tindakan dilatasi dan kuretase ini dapat digunakan untuk diagnostik, terapi, maupun aborsi pada trimester pertama (1).

Menurut penelitian di Department of Obstetrics and Gynaecology, Academic Medical Centre, Amsterdam, Belanda pada tahun 2014 menunjukkan bahwa pasien yang pernah melakukan tindakan dilatasi dan kuretase sebesar $13,7 \%$ dari 95 pasien (2). Di Indonesia sendiri, menurut laporan data di Ruang Bersalin RSUD dr. Adjidarmo Rangkasbitung, Kabupaten Lebak-Banten tahun 2014 tercatat terdapat 376 pasien bersalin dengan 71 orang (18.9\%) diantaranya memiliki riwayat tindakan dilatasi dan kuretase (3).

Lebih dari 40 juta pasien menjalani operasi setiap tahunnya di Amerika Serikat dan lebih dari 100 juta pasien di seluruh dunia sebanyak $30 \%$ mengalami kejadian mual dan muntah pascaoperasi (4). Terdapat laporan kejadian Postoperative Nausea and Vomiting (PONV) pada pasien yang menjalani anestesi umum di Amerika Latin, laporan tersebut didapat dari beberapa rumah sakit yang ada di Kolombia sebesar $10.9 \%$ dan di Kuba sebesar 15,4\%. Di Brazil, sebuah penelitian melaporkan $18,5 \%$ pasien mengalami mual dan $8,5 \%$ pasien mengalami muntah selama periode pascaoperasi (5).

Tindakan dilatasi dan kuretase menimbulkan rasa nyeri walaupun rasa nyeri ini berbeda setiap orangnya. Maka dari itu anestesi umum dipakai sebagai teknik standar manajemen nyeri pada tindakan operasi (1). Anestesi umum merupakan anestesi yang paling sering digunakan pada tindakan operasi dibanding anestesi lainnya. Sebanyak $70-80 \%$ kasus pembedahan memerlukan tindakan anestesi umum (6). Meskipun anestesi umum sering dilakukan untuk pembedahan, jenis anestesi ini menimbulkan beberapa komplikasi salah satunya yaitu kejadian mual dan muntah pascaoperasi atau PONV. Kejadian mual dan muntah pascaoperasi cukup tinggi sekitar 36\% pada pasien yang menjalani anestesi umum (7).

Di Italia sebuah penelitian pada tahun 2010 dilakukan dengan jumlah pasien 198 orang. Dari jumlah pasien tersebut 101 diantaranya menggunakan jenis obat anestesi intravena propofol dan 97 lainnya menggunakan jenis obat anestesi inhalasi sevoflurane. Pasien yang mendapat obat anestesi intravena propofol mengalami kejadian PONV sebesar 43,8\% sedangkan pada pasien yang diberikan obat anestesi inhalasi sevoflurane adalah sebesar 64,6\% (8). Kejadian PONV juga dikaitkan dengan status ASA, berdasarkan penelitian oleh Lausanne University Hospital di Swiss pada tahun 2016, pasien dengan status ASA I mengalami PONV sebesar $12,8 \%$, pasien dengan status ASA II sebesar 61,7\%, dan pasien dengan status ASA III sebesar 25,5\% (9).

Penelitian yang dilakukan pada tahun 2011 di Bangkok, Thailand dengan subjek penelitian sebanyak 390 pasien yang diberikan anestesi umum, didapatkan kejadian PONV dari berbagai kelompok usia. Kejadian PONV pada kelompok usia kurang dari 10 tahun didapatkan sebanyak 19 orang $(35,8 \%)$, usia $10-19$ tahun 
sebanyak 10 orang (20\%), usia $20-29$ tahun sebanyak 52 orang $(34,2 \%)$, usia 30 39 tahun sebanyak 10 orang $(17,9 \%)$ dan usia lebih dari sama dengan 40 tahun sebanyak 3 orang (4,9\%). Dari data tersebut terlihat bahwa pasien yang berusia dibawah 30 tahun memiliki resiko yang lebih tinggi untuk terjadinya Postoperative Nausea and Vomiting (PONV) (10). Di Indonesia pada tahun 2017 di RSUP Dr. Hasan Sadikin Bandung (RSHS), dengan subjek penelitian sebanyak 100 pasien, ditemukan kejadian PONV terdapat sebesar $42 \%$ dengan kejadian paling banyak terjadi pada 6 jam pascaoperasi (11).

Berdasarkan gambaran data diatas bahwa angka tindakan dilatasi dan kuretase cukup tinggi dan anestesi umum sering digunakan pada tindakan tersebut, hal ini dapat mengakibatkan kejadian Postoperative Nausea and Vomiting (PONV) sebagai salah satu komplikasi tersering dari anestesi umum. Meskipun hampir selalu hilang dengan sendirinya, kejadian mual dan muntah pascaoperasi ini dapat menyebabkan ketidaknyamanan pada pasien. Penelitian ini bertujuan untuk mengetahui Gambaran Kejadian Postoperative Nausea and Vomiting (PONV) pada Pasien Pasca Tindakan Dilatasi Kuretase dengan Anestesi Umum di RSIA B pada Tahun 2019 yang belum pernah diteliti pada tempat penelitian tersebut sebelumnya. Penelitian spesifik mengenai kejadian PONV pada tindakan kuretase juga masih sedikit ditemukan.

\section{METODE}

Desain penelitian yang dipakai untuk penelitian ini adalah penelitian deskriptif observasional. Penelitian ini dilaksanakan di Rumah Sakit Ibu dan Anak B Jl. Siliwangi No.189, Benda Baru, Kec. Pamulang, Kota Tangerang Selatan, Banten
15416 pada bulan November - Desember tahun 2020. Variabel pada penelitian ini adalah usia pasien yang menjalani tindakan dilatasi kuretase dengan anestesi umum dibagi menjadi rentang umur $17-22,23$ 28, 29 - 34, 35 - 40, $41-46$ dan $47-52$ tahun. Status ASA (American Society of Anesthesiologists) yaitu sistem penilaian untuk menilai status fisik pasien sebelum operasi. ASA dibagi menjadi 3 kategori yaitu ASA I apabila pasien normal dan sehat kriteria: sehat, tidak merokok, tidak atau hanya sedikit minum alkohol. ASA II apabila pasien dengan penyakit sistemik ringan, kriteria: perokok aktif, peminum alkohol yang sering, kehamilan, DM atau hipertensi yang terkontrol, penyakit paru ringan, $30<\mathrm{IMT}<40$. ASA III apabila pasien dengan penyakit sistemik yang berat kriteria: DM atau hipertensi yang tidak terkontrol dengan baik, PPOK, obesitas (IMT> 40), hepatitis aktif, ketergantungan atau penyalahgunaan alkohol, end-stage renal disease (ESRD) yang menjalani dialisis rutin.

Pembagian status ASA hanya diambil sampai ASA III dikarenakan untuk status ASA IV - VI termasuk kategori pasien dengan penyakit sistemik berat yang tidak dapat ditolong tanpa operasi sampai dengan kematian batang otak, sedangkan penelitian ini hanya meneliti pasien pasca tindakan dilatasi kuretase yang sehat maupun pasien dengan penyakit sistemik ringan sampai sedang. Jenis obat anestesi yang dipakai untuk menginduksi anestesi umum dibagi menjadi dua jenis yaitu obat anestesi inhalasi dan I.V, serta kejadian postoperative nausea and vomiting (PONV) yang didefinisikan sebagai mual dan atau muntah yang terjadi selama $24-48$ jam pertama setelah operasi pada pasien.

Populasi pada penelitian ini yaitu pasien pasca tindakan dilatasi kuretase 
dengan anestesi umum di RSIA B pada tahun 2019. Teknik sampling yang digunakan dalam penelitian ini adalah total sampling. Maka setiap pasien pasca tindakan dilatasi kuretase dengan anestesi umum dimasukkan dalam penelitian sesuai dengan periode yang telah ditetapkan serta berdasarkan kriteria inklusi dan eksklusi. Kriteria Inklusi: semua pasien pasca tindakan dilatasi kuretase dengan anestesi umum di RSIA B pada tahun 2019. Kriteria Eksklusi: pasien dengan data rekam medis tidak lengkap yaitu rekam medis yang tidak berisikan seluruh informasi tentang pasien sampai dengan catatan tindakan medis yang diberikan.

Data yang digunakan dalam penelitian ini adalah data sekunder yaitu berupa data rekam medis pasien yang menjalani tindakan dilatasi kuretase dengan anestesi umum di RSIA B pada tahun 2019. Penelitian ini telah mendapatkan persetujuan etik dari Komisi Etik Penelitian Kesehatan Fakultas Kedokteran dan Kesehatan Universitas Muhammadiyah Jakarta dengan nomor 083/PE/KE/FKK-UMJ/X/2020.

\section{HASIL}

Pasien yang menjalani tindakan dilatasi kuretase dengan anestesi umum di Rumah Sakit Ibu dan Anak B, Pamulang pada periode tahun 2019 didapatkan 139 sampel berdasarkan kriteria inklusi dan eksklusi.

Berdasarkan tabel 1 didapatkan usia pasien dengan persentase pasien terbanyak yang menjalani tindakan dilatasi kuretase dengan anestesi umum yaitu pada rentang usia 29 - 34 tahun sebanyak 50 sampel (36\%). Sedangkan jumlah terkecil didapatkan pada rentang usia 47 - 52 tahun sebanyak 1,4\%. Karakteristik Status ASA diketahui bahwa dari 139 sampel pada penelitian ini, didapatkan pasien dengan jumlah terbanyak berada pada status ASA I
$(66,2 \%)$ dan pasien dengan jumlah terkecil berada pada status ASA III $(0,7 \%)$. Jenis Obat Anestesi berdasarkan tabel 1 diketahui bahwa semua pasien yang menjalani tindakan dilatasi kuretase dengan anestesi umum memakai jenis obat anestesi intravena.

Tabel 1. Karakteristik Usia, Status ASA, dan Jenis Obat Anestesi yang Dipakai pada Pasien Pasca Tindakan Dilatasi Kuretase Dengan Anestesi Umum di RSIA B pada Tahun 2019

\begin{tabular}{lcc}
\hline $\begin{array}{c}\text { Karakteristik } \\
\text { Subjek }\end{array}$ & $\begin{array}{c}\text { Jumlah } \\
(\mathbf{n = 1 3 9 )}\end{array}$ & $\begin{array}{c}\text { Presentase } \\
(\boldsymbol{\%})\end{array}$ \\
\hline Usia & & \\
a. $17-22$ tahun & 6 & 4.3 \\
b. $23-28$ tahun & 42 & 30.2 \\
c. $29-34$ tahun & 50 & 36 \\
d. $35-40$ tahun & 24 & 17.3 \\
e. $41-46$ tahun & 15 & 10.8 \\
f. $47-52$ tahun & 2 & 1.4 \\
\hline Status ASA & & \\
a. Status ASA I & 92 & 66.2 \\
b. Status ASA II & 46 & 33.1 \\
c. Status ASA III & 1 & 0.7 \\
\hline Jenis Obat Anestesi & & \\
a. Intravena & 139 & 100 \\
b. Inhalasi & 0 & 0 \\
\hline
\end{tabular}

Tabel 2. Karakteristik Usia, Status ASA, dan Jenis Obat Anestesi yang Dipakai pada Pasien Pasca Tindakan Dilatasi Kuretase Dengan Anestesi Umum di RSIA B pada Tahun 2019

\begin{tabular}{lcccc}
\hline \multirow{2}{*}{ Variabel } & \multicolumn{2}{c}{ Kejadian } & \multicolumn{3}{c}{$\begin{array}{c}\text { Postoperative } \\
\text { Nausea }\end{array}$} \\
\cline { 2 - 5 } & Ya & $\%$ & Tidak & $\%$ \\
\hline Usia & & & & \\
$17-22$ & 0 & 0 & 6 & 100 \\
$23-28$ & 5 & 11,9 & 37 & 88,1 \\
$29-34$ & 7 & 14 & 43 & 86 \\
$35-40$ & 0 & 0 & 24 & 100 \\
$41-46$ & 3 & 20 & 12 & 80 \\
$47-52$ & 1 & 50 & 1 & 50 \\
Status ASA & & & & \\
ASA I & 12 & 13 & 80 & 87 \\
ASA II & 4 & 8,7 & 42 & 91,3 \\
ASA III & 0 & 0 & 1 & 100 \\
Jenis Obat Anestesi & & & \\
Intravena & 16 & 11,5 & 123 & 88,5 \\
Inhalasi & 0 & 0 & 0 & 0 \\
\hline \multicolumn{5}{r}{} \\
\hline
\end{tabular}


Tabel 2 berisi gambaran kejadian Postoperative Nausea and Vomiting (PONV) terhadap usia pasien yang menjalani tindakan dilatasi kuretase dengan anestesi umum, diperoleh jumlah terbanyak yang mengalami PONV yaitu berada pada rentang usia 29 - 34 tahun sebesar $14 \%$. Sedangkan pada pasien dengan rentang usia 17 - 22 tahun dan rentang usia 35 - 40 tahun tidak mengalami kejadian PONV. Jumlah terbanyak yang mengalami PONV yaitu berada pada status ASA I sebesar 13\%. $11.5 \%$ dari total 139 sampel yang memakai jenis obat anestesi intravena mengalami kejadian Postoperative Nausea and Vomiting (PONV).

\section{PEMBAHASAN}

\section{Gambaran Kejadian PONV dan Usia}

Pada penelitian ini karakteristik usia pada pasien pasca tindakan dilatasi kuretase dibagi menjadi enam rentang usia yang dimulai dari usia 17 sampai dengan 52 tahun, dan dengan masing - masing rentang usia berjarak lima tahun. Alasan pembagian usia seperti ini dikarenakan semua sampel yang di teliti adalah wanita, dimana pada wanita terdapat pengaruh hormon yang selalu berubah sesuai dengan usia, dari usia reproduktif kemudian pre-monopause dan menopause (12). Indikasi tindakan dilatasi kuretase juga dapat dilihat berdasarkan usia pasien. Pada pasien yang berusia lebih muda indikasi dilakukannya tindakan dilatasi kuretase adalah karena aborsi, sedangkan pada pasien yang berusia lebih tua, yang sudah mengalami menopause indikasi tindakan dilatasi kuretasenya adalah sebagai evaluasi perdarahan yang abnormal pada uterus.

Dalam penelitian yang dilakukan pada pasien yang menjalani tindakan dilatasi kuretase dengan anestesi umum di RSIA B pada tahun 2019, dari 139 sampel didapatkan usia pasien yang paling banyak menjalani tindakan dilatasi kuretase adalah pada rentang usia 29 - 34 tahun sebanyak 50 sampel (36\%). Hal tersebut sedikit berbeda dengan penelitian yang dilakukan di Surabaya pada tahun 2018 yaitu karakteristik usia pada pasien yang menjalani tindakan dilatasi kuretase didapatkan jumlah terbanyak pada rentang usia 23 - 28 tahun (13). Penelitian lain yang dilakukan pada tahun 2013 oleh Department of Obstetrics \& Gynecology, Shahid Sadoughi University of Medical Sciences, Iran menunjukkan dari 437 pasien yang termasuk dalam penelitian tersebut, didapatkan pasien yang menjalani tindakan dilatasi kuretase terbanyak berada pada rentang usia 23 - 31 tahun (14).

Berdasarkan usia, terdapat 16 pasien $(11.5 \%)$ yang mengalami kejadian Postoperative Nausea and Vomiting (PONV). Hal ini serupa dengan penelitian yang dilakukan oleh Duck Hwan Choi, dkk. kejadian PONV tertinggi didapatkan pada pasien yang memiliki usia sekitar 30 tahun (15). Namun penelitian lain yang dilakukan di Thailand pada tahun 2016, terdapat jumlah kejadian PONV tertinggi berada pada usia dibawah 30 tahun yaitu pada rentang usia 20 - 29 tahun sebanyak 52 sampel (34.2\%) (10). Penelitian yang dilakukan pada bulan Juli tahun 2015 di Tanzania didapatkan bahwa rentang usia pasien yang mengalami kejadian PONV terbanyak pada rentang usia 21 - 30 tahun sebanyak 80 pasien (46.5\%) (16).

Meskipun terdapat perbedaan dari rentang usia pasien yang paling banyak menjalani tindakan dilatasi kuretase, namun terlihat bahwa semua usia berada pada kategori rentang usia reproduktif dan dibawah 50 tahun. Kehamilan umumnya terjadi pada usia reproduktif, hal ini juga akan meningkatkan resiko terjadinya aborsi 
dan dilakukannya tindakan dilatasi kuretase. Insiden yang tinggi pada pasien muda ini mungkin disebabkan oleh fakta bahwa mereka lebih cenderung mengeluh tentang PONV dibandingkan pasien yang lebih tua. Ada juga kemungkinan bahwa pasien yang lebih muda mungkin memiliki tonus otonom yang tinggi dan merespon lebih buruk terhadap agen anestesi dan analgesik termasuk opioid. PONV dapat disebabkan dari berbagai macam rangsangan yaitu bahan kimia maupun pergerakan. Pada pasien yang berumur lebih muda, neuron aferen lebih sensitif terhadap rangsangan ini dan sinyal dari rangsang ini akan diteruskan ke pusat muntah di batang otak kemudian akan terjadi mual muntah. Sehingga pasien dengan usia muda memiliki batas ambang mual muntah yang lebih rendah dan resiko terjadinya PONV akan lebih tinggi dibanding dengan pasien yang berusia lebih tua (17). Namun, sampai sekarang belum ada penelitian yang pasti tentang usia dan pengaruhnya terhadap kejadian PONV(15).

\section{Gambaran Kejadian PONV dan Status} ASA

Status ASA dibagi menjadi status ASA I status ASA VI. Namun pada penelitian ini status ASA pasien pasca tindakan dilatasi kuretase dibagi menjadi tiga yaitu status ASA I, status ASA II, dan status ASA III. Pembagian seperti ini dikarenakan untuk status ASA IV - VI termasuk kategori pasien dengan penyakit sistemik berat yang tidak dapat ditolong tanpa operasi sampai dengan kematian batang otak, sedangkan penelitian ini hanya meneliti pasien pasca tindakan dilatasi kuretase yang sehat maupun pasien dengan penyakit sistemik ringan sampai sedang (9).

Pada penelitian ini didapatkan pasien yang menjalani tindakan dilatasi kuretase paling banyak terdapat pada status ASA I sebesar 92 sampel (66.2\%). Hal ini serupa dengan penelitian di KK Women's and Children's Hospital, Singapura pada tahun 2020 menunjukkan bahwa pasien yang menjalani tindakan dilatasi kuretase paling banyak terdapat pada pasien dengan status ASA I sebesar 78 pasien (72.2\%) (18). Penelitian lain yang dilakukan pada tahun 2015 oleh Department of Anesthesiology, Dr. S.N. Medical College, India juga menunjukkan bahwa status ASA terbanyak pada pasien yang menjalani tindakan dilatasi kuretase adalah status ASA I sebanyak 25 sampel (75\%) (19). Banyaknya pasien pasca tindakan dilatasi kuretase yang berada pada kategori status ASA I ini menunjukkan bahwa kondisi fisik pasien yang menjalani tindakan dilatasi kuretase berada pada kategori sehat dan tidak terdapat penyakit sistemik.

Kejadian Postoperative Nausea and Vomiting (PONV) pada penelitian ini terjadi paling banyak pada pasien dengan status ASA I yaitu sebanyak 12 sampel (13\%). Hasil pada penelitian ini serupa dengan penelitian yang dilakukan di Eropa pada tahun 2016, juga didapatkan pasien yang mengalami kejadian PONV terbanyak terdapat pada pasien dengan status ASA I sebanyak 52 pasien (20). Sedangkan penelitian lain yang dilakukan oleh Lausanne University Hospital di Swiss pada tahun 2016, pasien dengan status ASA II mengalami kejadian PONV paling banyak yaitu sebesar $61,7 \%$ (9).

Klasifikasi status ASA mungkin terkait dengan resiko kejadian PONV, dimana pasien yang diklasifikasikan sebagai status ASA I dan II (mempunyai status fisik lebih baik) lebih sering mengalami kejadian PONV dibandingkan pasien yang mempunyai komorbiditas dan berada pada status ASA III atau lebih. Pasien yang berada pada status ASA III dan 
lebih memiliki setidaknya satu penyakit sistemik sedang hingga berat, salah satu contohnya yaitu penyakit DM yang tidak terkontrol. Pada DM yang tidak terkontrol dapat terjadi neuropati saraf otonom, hal ini dapat menyebabkan saraf aferen yang menerima rangsangan mual muntah tidak sensitif sehingga terdapat gangguan penghantaran sinyal dari rangsangan ke pusat muntah di batang otak. Maka dari itu, pasien yang memiliki penyakit sistemik berat biasanya memiliki batas ambang mual muntah yang lebih baik daripada pasien yang sehat. Resiko terjadinya PONV pada pasien ini pun lebih rendah daripada pasien yang sehat dan tidak mempunyai penyakit sistemik. Meskipun demikian, penelitian yang dilakukan oleh Lenka, dkk. ini menunjukkan bahwa tidak ada korelasi yang signifikan antara status ASA dengan kejadian PONV (21).

Klasifikasi status ASA mungkin terkait dengan resiko kejadian PONV, dimana pasien yang diklasifikasikan sebagai status ASA I dan II (mempunyai status fisik lebih baik) lebih sering mengalami kejadian PONV dibandingkan pasien yang mempunyai komorbiditas dan berada pada status ASA III atau lebih. Pasien yang berada pada status ASA III dan lebih memiliki setidaknya satu penyakit sistemik sedang hingga berat, salah satu contohnya yaitu penyakit DM yang tidak terkontrol. Pada DM yang tidak terkontrol dapat terjadi neuropati saraf otonom, hal ini dapat menyebabkan saraf aferen yang menerima rangsangan mual muntah tidak sensitif sehingga terdapat gangguan penghantaran sinyal dari rangsangan ke pusat muntah di batang otak. Maka dari itu, pasien yang memiliki penyakit sistemik berat biasanya memiliki batas ambang mual muntah yang lebih baik daripada pasien yang sehat. Resiko terjadinya PONV pada pasien ini pun lebih rendah daripada pasien yang sehat dan tidak mempunyai penyakit sistemik. Meskipun demikian, penelitian yang dilakukan oleh Lenka, dkk. ini menunjukkan bahwa tidak ada korelasi yang signifikan antara status ASA dengan kejadian PONV (21).

\section{Gambaran Kejadian PONV dan Jenis Obat Anastesi}

Pada penelitian ini didapatkan semua pasien yang menjalani tindakan dilatasi kuretase di RSIA B pada tahun 2019, menggunakan jenis obat anestesi umum intravena. Hasil pada penelitian ini sejalan dengan penelitian lainnya. Penelitian yang dilakukan di RSUP Dr. Hasan Sadikin, Bandung pada tahun 2018 dengan subjek penelitian sebanyak 36 pasien yang melakukan tindakan dilatasi kuretase, didapatkan seluruhnya menggunakan jenis obat anestesi umum intravena (22). Pada tahun yang sama, penelitian yang dilakukan di Amerika dengan pasien yang menjalani tindakan dilatasi kuretase sebanyak 150 pasien tercatat bahwa semuanya juga menggunakan jenis obat anestesi umum intravena (23).

Anestesi umum intravena merupakan jenis anestesi yang sering digunakan pada tindakan operasi minor termasuk dalam tindakan dilatasi kuretase. Banyaknya pemakaian anestesi umum intravena ini dikarenakan onset yang cepat, durasi yang pendek, pelepasan histamin minimal, dan cara pemberian yang mudah dengan kualitas amnesia, analgetik dan antiemetik yang cukup baik sehingga anestesi ini menjadi pilihan pertama pada tindakan dilatasi kuretase (22).

Dari 139 sampel, 16 sampel (11.5\%) yang memakai jenis obat anestesi intravena mengalami kejadian Postoperative Nausea and Vomiting (PONV). Namun, kejadian 
PONV pada penelitian ini memiliki jumlah yang lebih kecil dibandingkan dengan penelitian yang memakai jenis obat anestesi umum inhalasi. Penelitian yang dilakukan oleh Anesthesiology \& Intensive Care Department, Kairo pada tahun 2012 juga menunjukkan hasil yang serupa yaitu angka kejadian PONV paling tinggi terjadi pada pasien yang memakai jenis obat anestesi umum inhalasi sevoflurane sebesar 12 sampel (40\%), sedangkan pasien yang memakai jenis obat anestesi umum intravena hanya sedikit yang mengalami kejadian PONV yaitu pada pasien yang memakai anestesi umum intravena ketamine sebesar 4 sampel $(13.3 \%)$ dan pasien yang memakai anestesi umum intravena propofol hanya sebesar 2 sampel (6.7\%) (24).

Penelitian lain pada tahun 2016 di Jepang, didapatkan bahwa kejadian PONV pada pasien yang memakai jenis obat anestesi inhalasi lebih tinggi yaitu sebanyak $78 \%$ sedangkan pada pasien yang memakai jenis obat anestesi intravena didapatkan kejadian PONV hanya sebesar 26\% (25).

Tingginya angka kejadian PONV pada pasien yang memakai jenis obat anestesi umum inhalasi mungkin disebabkan karena peningkatan distensi abdomen akibat pertukaran gas yang dimasukkan ke dalam saluran gastrointestinal selama ventilasi masker, hal ini dapat merangsang mekanoreseptor yang terdapat pada dinding otot saluran gastrointestinal dan mengalirkan sinyal ke pusat muntah (26). Sedangkan pada jenis obat anestesi intravena, obat anestesi setelah disuntikkan akan segera berjalan di pembuluh darah dan bersirkulasi hingga masuk ke dalam otak dan membuat pasien dalam keadaan tidak sadar. Hal ini akan memperkecil resiko terjadinya PONV dibandingkan dengan pemakaian jenis obat anestesi inhalasi. Namun, sedikitnya angka kejadian PONV pada penelitian ini selain disebabkan karena memakai jenis obat anestesi umum intravena, dapat juga disebabkan karena adanya faktor lain seperti pemberian prophylaxis antiemetic yang dapat menurunkan angka kejadian PONV. Penelitian pada tahun 2015 di Cina menunjukkan bahwa pasien yang mendapatkan prophylaxis antiemetic yang diberikan sebelum tindakan operasi akan menurunkan angka resiko kejadian PONV hingga $27.5 \%$ (27). Prophylaxis antiemetic yang sering digunakan salah satunya yaitu ondansetron. Ondansetron merupakan obat lini pertama yang efektif mengatasi mual muntah pada 24 jam pertama pasca operasi dan dosis yang diberikan yaitu $4-8 \mathrm{mg}$ secara intravena. Mekanisme dari obat ini adalah memblokir reseptor 5HT-3 yang berada di CTZ (Chemoresptor Trigger Zone) sehingga resiko terjadinya PONV dapat diminimalisir dengan pemberian obat ini (28).

\section{SIMPULAN}

Kejadian Postoperative Nausea and Vomiting (PONV) pada 139 pasien yang menjalani tindakan dilatasi kuretase dengan anestesi umum di RSIA B pada tahun 2019 paling banyak terjadi pada rentang usia produktif yaitu 29 - 34 tahun, pasien dengan status ASA I dan yang memakai jenis obat anastesi intravena.

\section{UCAPAN TERIMA KASIH}

Penulis mengucapkan terima kasih kepada semua pihak terutama FKK UMJ dan RSIA B yang telah membantu proses penelitian ini.

\section{KONFLIK KEPENTINGAN}

Penulis menyatakan tidak memiliki konflik kepentingan apapun. 


\section{REFERENSI}

1. Ksyatria YNI, Pradjatmo H, Emilia O. Perbandingan Skala Nyeri pada Kuretase antara Pemberian Lidokain Paraservikal dan Intraservikal. J Kesehat Reproduksi. 2016 Apr 22;3(1):1.

2. Lemmers $\mathrm{M}$, Verschoor MAC, Overwater K, Bossuyt PM, Hendriks D. Fertility and obstetric outcomes after curettage versus expectant management in randomised and nonrandomised women with an incomplete evacuation of the uterus after misoprostol treatmen. Eur $\mathbf{J}$ Obstet Gynecol Reprod Biol. 2017;211:78-82.

3. Kadar K, Ulviyatulillah. Hubungan Riwayat Abortus dan Riwayat Kuretase Dengan Kejadian Plasenta Previa. J Obs Sci. 2017;4:401-17.

4. Smith HS, Smith EJ, Smith BR, Department. Postoperative nausea and vomiting. $\mathrm{Br} \mathrm{J}$ Hosp Med (Lond). 2012;81(6):1-3.

5. Shiraishi-zapata CJ, Arellanoadrianzén SJ. Cumulative incidence and risks factors for postoperative nausea and vomiting in adult patients undergoing cholecystectomy under balanced general anesthesia: a prospective cohort study Incidencia acumulada y factores de. Colomb J Anesthesiol. 2020;48(1):3-11.

6. Okta IB, Subagiartha IM, Wiryana M. Perbandingan Dosis Induksi dan Pemeliharaan Propofol Pada Operasi Onkologi Mayor yang Mendapatkan Pemedikasi Gabapentin dan Tanpa Gabapentin. JAI (Jurnal Anestesiol Indones. 2017 Nov 1;9(3):136.

7. Elizahaf RA, Ajroud S. A Prospective Survey of Postoperative Nausea and Vomiting: Its Prevalence and Risk Factors. Libyan J Med Sci. 2018;2(March):38-64.

8. Vari A, Gazzanelli S, Cavallaro G, De Toma G, Tarquini S, Guerra C, et al. Post-operative nausea and vomiting (PONV) after thyroid surgery: a prospective, randomized study comparing totally intravenous versus inhalational anesthetics. Am Surg. 2010 Mar;76(3):325-8.

9. Sansonnens J, Taffé P, Burnand B. Higher occurrence of nausea and vomiting after total hip arthroplasty using general versus spinal anesthesia: an observational study. BMC Anesthesiol. 2015 Dec 26;16(1):44.

10. Apipan B, Rummasak D, Wongsirichat N. Postoperative nausea and vomiting after general anesthesia for oral and maxillofacial surgery. J Dent Anesth Pain Med. 2016;16(4):273.

11. Hendro RT, Pradian E, Indriasari I. Penggunaan Skor Apfel Sebagai Prediktor Kejadian Mual dan Muntah Pascaoperasi di RSUP Dr. Hasan Sadikin Bandung. J Anestesi Perioper. 2018;6(2):89-97.

12. Venkatesh $\mathrm{KK}, \mathrm{Cu}-\mathrm{Uvin} \mathrm{S}$. Anatomic and Hormonal Changes in the Female Reproductive Tract Immune Environment during the Life Cycle: Implications for HIV/STI Prevention Research. Am J Reprod Immunol. 2014;71(6):495504.

13. Herawati F, Rahem A, Handayani DWI, Yulia R. Antibiotic prophylactics on curettage for preventing pelvic inflammatory disease events: Is it necessary? Asian J Pharm Clin Res. 2018;11(11):2679. 
14. Davar R, Dehghani Firouzabadi R, Chaman Ara K. Dilatation and curettage effect on the endometrial thickness. Iran Red Crescent Med J. 2013;15(4):350-5.

15. Choi DH, Ko JS, Ahn HJ, Kim JA. A Korean Predictive Model for Postoperative Nausea and Vomiting. J Korean Med Sci. 2005;20(5):811.

16. Phillipo C, Joseph M. Postoperative nausea and vomiting at a tertiary care hospital in north- western Tanzania. 2015;17(3):1-9.

17. Amponsah G. Postoperative nausea and vomiting in korle bu teaching hospital. Ghana Med J. 2010;41(4):181-5.

18. Chan JJI, Yeam CT, Kee HM, Tan CW, Sultana R, Sia ATH, et al. The use of pre-operative virtual reality to reduce anxiety in women undergoing gynecological surgeries: a prospective cohort study. BMC Anesthesiol. 2020 Dec 9;20(1):261.

19. Sethi P, Sindhi S, Verma A, Tulsiani KL. Dexmedetomidine versus propofol in dilatation and curettage: An open-label pilot randomized controlled trial. Saudi J Anaesth. 2015;9(3):258-62.

20. Aljabari A, Massad I, Alzaben K. Post-Operative Nausea , Vomiting and Pain Score in Post Anesthesia Care Unit ( PACU ) at Jordan University Hospital. J Anesth Clin Res. 2016;7(1):1-4.

21. Doubravska L, Dostalova K, Fritscherova S, Zapletalova J, Adamus M. Incidence of Postoperative Nausea and Vomiting In Patients at a University Hospital. Where Are We Today? Biomed Pap. 2010 Mar 1;154(1):69-76.

22. Lewoleba R, Singarimbun D,
Maskoen T. Perbandingan

Kedalaman Sedasi antara Deksmedetomidin dan Kombinasi Fentanil-Propofol Menggunakan Bispectral Index Score pada Pasien yang Dilakukan Kuretase. Perbandingan Kedalaman Sedasi antara Deksmetomidin dan Komb Fentanil Propofol. 2018;6(1):80-8.

23. Yousefian M, Farzipour S, Noroozi $\mathrm{V}$, Salmanfar T, Salmanfar T, Hospital A. Comparative Study of Ketofol and Thiopental Sodium in Patients undergoing Dilation and Curettage by General Anesthesia. 2018;13.

24. Sheikhzade D, Razaghipour M, Seyedhejazi M, Aliakbari Sharabiani B, Marahem M. A Comparison of the Sevoflurane and Total Intravenous Anesthesia on the Quality of Recovery in 2 to 10 -YearOld Children. Iran $\mathbf{J}$ Pediatr [Internet]. 2020 Dec 7;31(1). Available from: https://sites.kowsarpub.com/ijp/artic les/105900.html

25. Matsuura H, Inoue S, Kawaguchi M. Acta Anaesthesiologica Taiwanica The risk of postoperative nausea and vomiting between surgical patients received propofol and sevo fl urane anesthesia: A matched study. Acta Anaesthesiol

Taiwanica. 2016;54(4):114-20.

26. Shaikh S, Nagarekha D, Hegade G, Marutheesh M. Postoperative nausea and vomiting: A simple yet complex problem. Anesth Essays Res. 2016;10(3):388.

27. Yu W, Li Q, Gong J. Surgery: Current Research The Prophylaxis and Treatment with Ondansetron for Postoperative Nausea and Vomiting. 
2015;5(2):2014-6.

28. Zhang D, Shen Z, You JIE, Zhu X, Tang Q. Effect of ondansetron in preventing postoperative nausea and vomiting under different conditions of general anesthesia : A preliminary , randomized, controlled study. 2013;(January):87-90. 